\title{
Analysis and Design of Sequential Digital Systems
}


Other titles in Electrical and Electronic Engineering

J. C. Cluley: ELECTRONIC EQUIPMENT RELIABILITY

R. F. W. Coates: MODERN COMMUNICATION SYSTEMS

W. Gosling: A FIRST COURSE IN APPLIED ELECTRONICS

B. A. GREGORY: AN INTRODUCTION TO ELECTRICAL INSTRUMENTATION

Paul A. Lynn: AN INTRODUCTION TO THE ANALYSIS AND PROCESSING OF SIGNALS

A. G. Martin and F. W. Stephenson: LINEAR MICROELECTRONIC SYSTEMS

J. E. Parton and S. J. T. Owen: APPLIED ELECTROMAGNETICS

A. Potton: AN INTRODUCTION TO DIGITAL LOGIC

J. T. Wallmark and L. G. Carlstedt: FIELD-EFFECT TRANSISTORS IN INTEGRATED CIRCUITS

G. Williams: AN INTRODUCTION TO ELECTRICAL CIRCUIT THEORY 


\section{Analysis and Design of Sequential Digital Systems}

\section{F. Lind}

Department of Electrical Engineering Science, University of Essex

\section{J. C. C. Nelson}

Department of Electrical and Electronic Engineering, University of Leeds 
(C) L. F. Lind and J. C. C. Nelson 1977

All rights reserved. No part of this publication may be reproduced or transmitted, in any form or by any means, without permission

First published 1977 by

THE MACMILLAN PRESS LTD

London and Basingstoke

Associated companies in New York Dublin

Melbourne Johannesburg and Madras

ISBN 978-0-333-19267-2

ISBN 978-1-349-15757-0 (eBook)

DOI 10.1007/978-1-349-15757-0

Set in Monophoto Times by Doyle Photosetting Ltd, Tullamore, Ireland

Printed by Unwin Brothers Limited, The Gresham Press, Old Woking, Surrey.

This book is sold subject to the standard conditions of the Net Book Agreement.

The paperback edition of this book is sold subject to the condition that it shall not, by way of trade or otherwise, be lent, re-sold, hired out, or otherwise circulated without the publisher's prior consent in any form of binding or cover other than that in which it is published and without a similar condition including this condition being imposed on the subsequent purchaser. 


\section{Contents}

Preface

vii

1. Introduction 1

1.1 What are Digital Systems 1

1.2 How are Digital Systems Realised? 2

1.3 Binary Representation of Quantities 3

1.4 Serial and Parallel Data 4

1.5 Comparison of Analogue and Digital Systems 4

2. Review of Combinational-logic Techniques 5

2.1 Logic Levels 5

2.2 Gates 6

2.3 The Karnaugh Map 12

2.4 Partitioning 20

2.5 Iterative Circuits 22

2.6 Multiple Outputs 23

2.7 Concluding Remarks 24

2.8 Examples 24

References $\quad 28$

3. Introduction to Sequential Systems 29

3.1 Fundamental Concepts 29

3.2 Storage Devices 32

3.3 Sequential Sub-systems 38

3.4 Intuitive Design of Sequential Systems 47

3.5 Examples 49

References $\quad 53$

4. Asynchronous Sequential Systems $\quad 54$

4.1 Basic Concepts 54

4.2 Analysis Techniques $\quad 57$

4.3 Races and Hazards 63

4.4 System Design 68

$\begin{array}{llr}4.5 & \text { Examples } & 87\end{array}$

$\begin{array}{ll}\text { References } & 102\end{array}$ 
5. Synchronous Sequential Systems 104

5.1 Advantages and Disadvantages of Synchronous Systems 104

5.2 Preliminary Design

5.3 Flow-chart Method of Design

5.4 Pictorial Aids

5.5 State Assignment

5.6 Examples

6. Practical Design Considerations

6.1 Initial Specification

6.2 Detailed Design

6.3 Prototype Development

6.4 Printed-circuit Boards

6.5 Testing and Documentation

References

Appendix

Index 


\section{Preface}

This text presents the basic information required for successful design of modern logic systems. The information is presented in a form that should be immediately applicable by practising engineers but that also forms the basis of a comprehensive final-year university or polytechnic course. It will also prove useful to postgraduates in disciplines relying on the application of digital methods, for example, computer science, control engineering and instrumentation.

Certain mathematical theorems relating to Boolean variables are excluded for over-all clarity. The use of these theorems to simplify Boolean expressions has, in large part, been superseded by mapping and tabular techniques. Excessive treatment of the mathematical basis of some of the procedures would tend to obscure the engineering concepts involved.

The theoretical material is illustrated with practical examples wherever possible. The examples can be used for extending the reader's knowledge from the particular to the general, which, in many cases, appears to be a more natural approach than the reverse. Wide use of references is made where this is felt desirable, to free the text from detail not immediately relevant and to provide a basis for further reading.

An important feature of the book is the consideration of logic design from a human point of view. An attempt is made to relate the more formal design techniques to the widely used intuitive or 'cut-and-try' approach. For example, the problem of state assignment is simplified by considering only those possibilities that fit in with a natural (or human) approach to the problem. This consideration has repercussions in all phases of the design procedure. One of the most important results lies in the increased understanding of the operations of the circuit by service personnel. Also, by requiring the solution to look 'natural', the number of possibilities is greatly reduced (sometimes to one), thereby reducing the amount of design time required.

The partitioning of one complex circuit into a number of smaller circuits is also carefully considered. To date there is no automatic procedure for doing this; instead, ad hoc solutions are generally used. Guidelines are laid down for accomplishing this partitioning in this book. Again, 'naturalness' is the keynote of the partitioning procedure. A well-partitioned circuit should be relatively simple to test and troubleshoot, which leads to enormous practical advantages in the post-design career of the circuit. 
Particular attention is devoted to hazards, races and other phenomena that, although not apparent from a superficial appraisal of a proposed design, can lead to mal-operation. Careful attention to these points, together with the information provided in the final chapter on practical implementation, should lead to the production of reliable designs every time.

The authors would like to thank R. Coleman, Technical Director of Trend Communications Ltd, for his assistance with chapter 6 . They would also like to thank Mrs S. Nelson for her accuracy and patience in typing the manuscript. 